Perspective

\title{
Sell a dummy: Adjacent functional group modification strategy for the catalytic cleavage of lignin $\beta-0-4$ linkage
}

\author{
Chaofeng Zhang, Feng Wang *
}

\section{Making a feint to the east and attacking in the west. -----Huainanzi·Bingluexun}

The world relies on nonrenewable fossil resources, which provide various fuels, chemicals and materials. Biomass is another storage form of carbon and solar energy that has attracted great interest, mainly because of its potential as a sustainable source of chemicals and fuels [1,2]. Lignin is an attractive biomass feedstock. As shown in Fig. 1, three phenylpropane units assemble into lignin with a complex three-dimensional structure and different linkages in plants [3]. Lignin is regarded as an alternative resource to oil for preparing aromatics. Alt- hough different lignin has different linkages distributions, $\beta-0-4$ linkage is the most abundant in both softwood and hardwood lignin. Therefore, selective cleaving of $\beta-0-4$ linkage has become a hot topic in the past several years [1,2].

In recent years, studies have been directed towards the depolymerization of native lignin residing in wood. These reactions are performed at high temperature in hydrocarbon solvents. The product contains lignin fragments, aromatics and cyclohexane derivatives. In 2013, we reported for the first time that methanol was a suitable solvent for converting native birch lignin over a nickel supported on activated carbon (Ni/AC) catalyst via a fragmentation-hydrogenolysis process

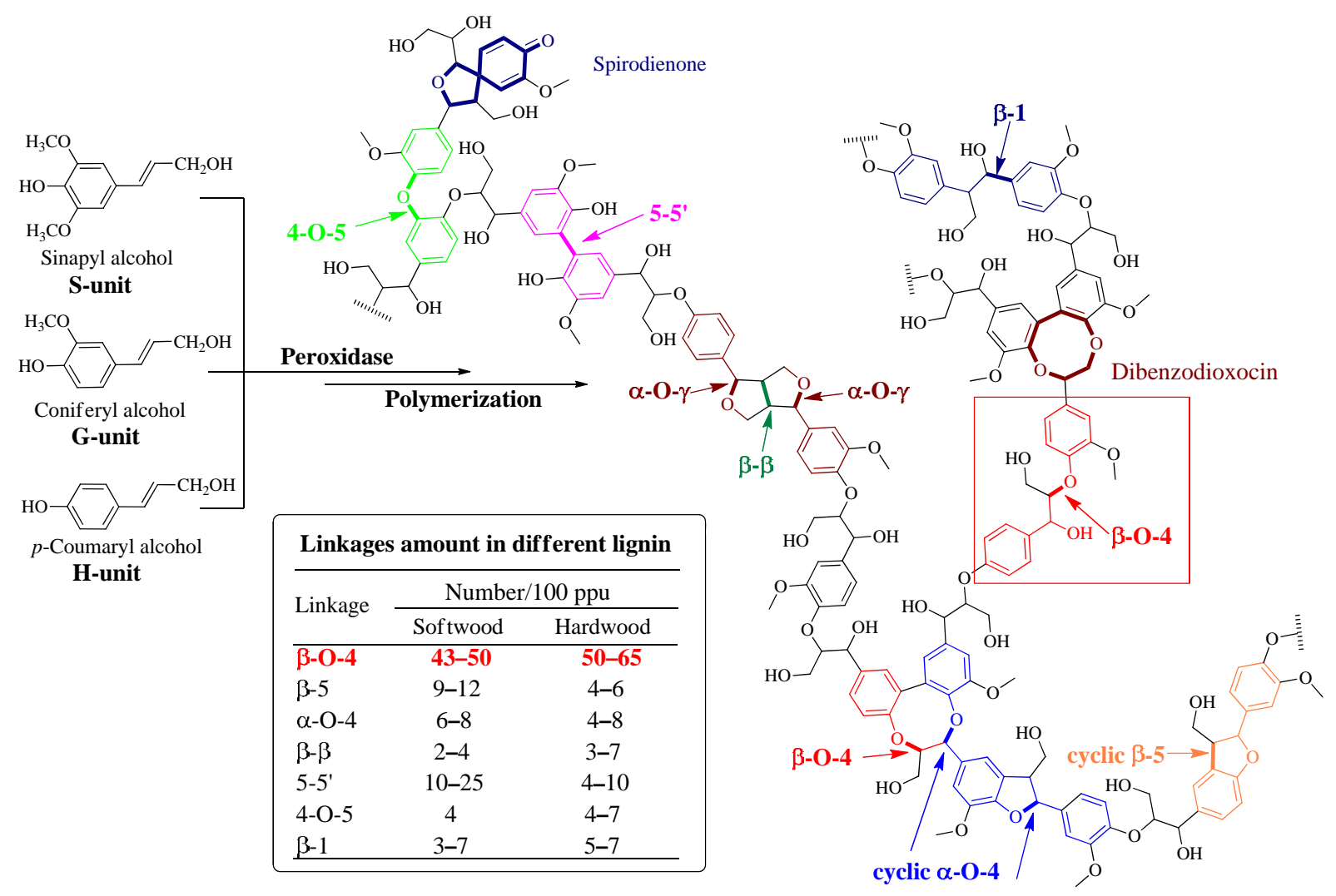

Fig. 1. Common lignin linkages and their approximate abundance in softwood and hardwood lignin. 
[4]. Our further work showed that Ni catalysts could also catalyze the hydrogenolysis of lignin sulfonate with a high content of sulfur to aromatics in ethanediol [5]. Since then, more studies have shown that an alcohol solvent was a preferred choice for native lignin conversion. As well as the outstanding performance of $\mathrm{Ni} / \mathrm{AC}$ catalyst prepared by carbothermic reduction in an alcohol solvent $[4,5]$, we have also shown that the unique structure of $\mathrm{Ni} / \mathrm{AC}$ has an obvious effect on the conversion route of lignin depolymerization [6]. However, the native lignin conversion process is overwhelmingly complex, which obstructs further works to promote the catalytic ability of known catalysts.

Different from the approach of the direct depolymerization of native lignin, another protocol termed bottom-up focuses on the mechanism of cleaving the typical $\mathrm{C}-\mathrm{O}$ or $\mathrm{C}-\mathrm{C}$ bonds in lignin model compounds at the molecular level. Although there is a vast difference between studies on model compounds and studies on native lignin, because of the complex lignin structure, the bottom-up approach has presented many effective catalytic systems and strategies in the native lignin conversion.

Selective cleaving of basic $\mathrm{C}_{\alpha}-\mathrm{C}_{\beta}$ or $\mathrm{C}_{\beta}-\mathrm{OAr}$ bonds in the $\beta-0-4$ lignin model can obtain two phenyl units. To achieve this goal, different methods focusing on new reaction routes have been reported in the past 8 years. During this period, our group has performed some studies on the $\beta-0-4$ lignin model conversion. Our strategy is to "sell a dummy" on the lignin structure. (Note: As the Huainanzi-Bingluexun quote says, "Sell a dummy" means making a feint on the east and attacking in the west.) Our strategies mainly begin with adjacent functional group modification (AFGM, Fig. 2), which can directly decrease the bond dissociation enthalpy (BDE) of targeted bonds or introduce new "substrate sites" for further conversion. These two ideas combining with appropriate catalytic systems can make the conversion of $\beta-0-4$ lignin model efficient and selective.

As shown in Fig. 2, the first oxidation of $\mathrm{C}_{\alpha}-\mathrm{OH}$ to $\mathrm{C}_{\alpha}=0$ $(\beta-0-4$ alcohol $\rightarrow \mathbf{I}-1)$ can reduce about $90 \mathrm{~kJ} / \mathrm{mol} \mathrm{BDE}$ of the $\mathrm{C}_{\beta}-\mathrm{OAr}$ bond [7]. Thus, the $\mathrm{C}_{\beta}-\mathrm{OAr}$ bond connected with a $\mathrm{C}_{\alpha}=0$

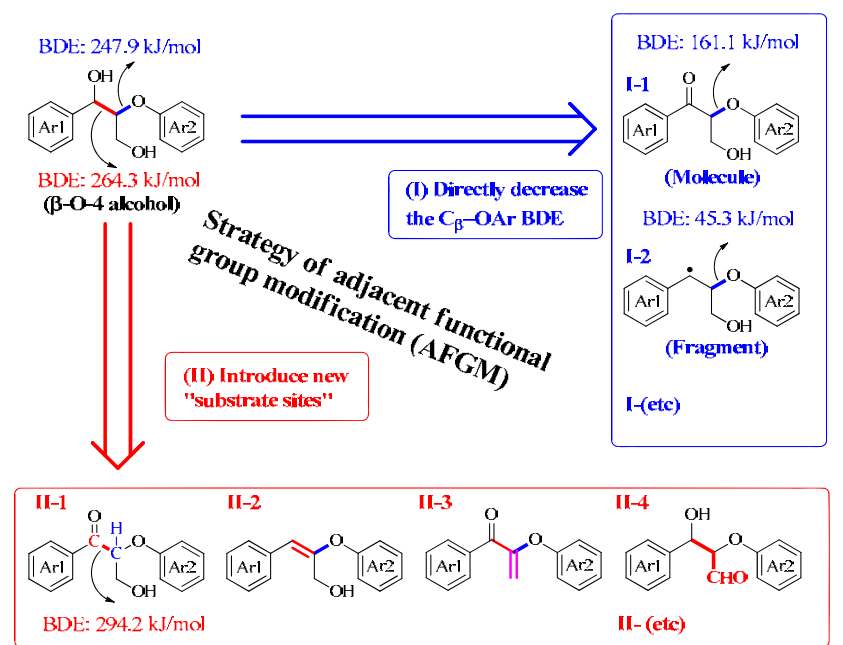

Fig. 2. Strategy of adjacent functional group modification (AFGM) for the cleavage of basic $C_{\alpha}-C_{\beta}$ and $C_{\beta}-0 A r$ bonds in $\beta-0-4$ lignin linkage. The bond dissociation enthalpy (BDE) values of $\mathrm{C}_{\alpha}-\mathrm{C}_{\beta}$ and $\mathrm{C}_{\beta}-\mathrm{OAr}$ refer to the compounds with $\operatorname{Ar} 1=\operatorname{Ar} 2=-\mathrm{C}_{6} \mathrm{H}_{5}$. can be cleaved easily with metal powders in an acid solution via an uncatalyzed process [8]. The reductive species could be the $\mathrm{H}^{+}$and $\mathrm{e}^{-}$generated from the reaction of metal and acid. To cleave the $\mathrm{C}_{\beta}-\mathrm{OAr}$ bond in a catalytic process, we used $\mathrm{TiO}_{2}$ with an abundance of $\mathrm{Ti}^{3+}$ on the surface to efficiently catalyze the photocleavage of the $\mathrm{C}_{\beta}-\mathrm{OAr}$ bond in $\beta-0-4$ lignin ketones models with $\mathrm{H}^{+}$and $\mathrm{e}^{-}$under $365 \mathrm{~nm}$ irradiation [9], during which sodium acetate promotes the generation of $\mathrm{H}^{+}$from the consumption of ethanol (Fig. 3). In addition, the Pd/ZnIn $2 \mathrm{~S}_{4}$ can catalyze the photocatalytic oxidation of $\mathrm{C}_{\alpha}-\mathrm{OH}$ in $\beta-0-4$ alcohols to $\mathrm{C}_{\alpha}=0$ with $455 \mathrm{~nm}$ light.

To achieve the first transformation of $\mathrm{C}_{\alpha}-\mathrm{OH}$ to $\mathrm{C}_{\alpha}=\mathrm{O}$ and the consequent hydrogenolysis or reduction cleavage of $\mathrm{C}_{\beta}-\mathrm{OAr}$ bond, besides the first selective oxidation $[8,10]$, the transfer-hydrogenation process could be an atom economical method [11-14]. We have shown that $\mathrm{Pd} / \mathrm{C}$ catalyzes the transformation of $\beta$-0-4 lignin model to phenol and ketone via a dehydrogenation-hydrogenation process, and performed density functional theory calculations to investigate the cleavage mechanism of the $\mathrm{C}_{\beta}-\mathrm{OAr}$ ether bond in 2-phenoxy-1-phenylethanol over the Pd(111) surface [15]. The favorable reaction pathway (Fig. 4, in red) proceeds as follows: the lignol $\mathbf{2 a}$ is first dehydrogenated to generate its corresponding ketone $\mathbf{2 e}$; the ketone continues to dehydrogenate on the $\mathrm{C}_{\beta}$ by a first equilibrated keto-enol tautomerization to its enol form $\mathbf{2 f}$ and then $-\mathrm{OH}$ dehydrogenation; the $\mathrm{C}_{\beta}-\mathrm{OAr}$ ether bond cleavage happens afterward, leading to surface intermediates (1j and $\mathbf{1 d})$ followed by hydrogenation to yield acetophenone and phenol.

Because there are other ether linkages $(\alpha-0-4,4-0-5)$ present without an adjacent hydroxyl group to provide an active hydrogen, converting lignin via oxidation-hydrogenation strategy is still a feasible method. However, the uncontrolled hydrogenation system can catalyze the hydrogenation of aromatic rings, and the ketone can hydrogenate back to alcohol before the $\mathrm{C}_{\beta}-\mathrm{OAr}$ cleavage. Thus, the hydrogenation system should prefer to catalyze the cleavage of $\mathrm{C}_{\beta}-\mathrm{OAr}$ rather than hydrogenate the $\mathrm{C}_{\alpha}=0$ bond or aromatic rings. We have shown that NiMo sulfide is an appropriate catalyst for this purpose (Fig. 5) [16]. Because the hydrogenative edge Mo sites of $\mathrm{MoS}_{2}$ are in a linear arrangement (Fig. 5(D)) and the Mo sites are the active sites to cleave $\mathrm{C}_{\beta}-\mathrm{OAr}$ bonds, there are few Mo sites available as

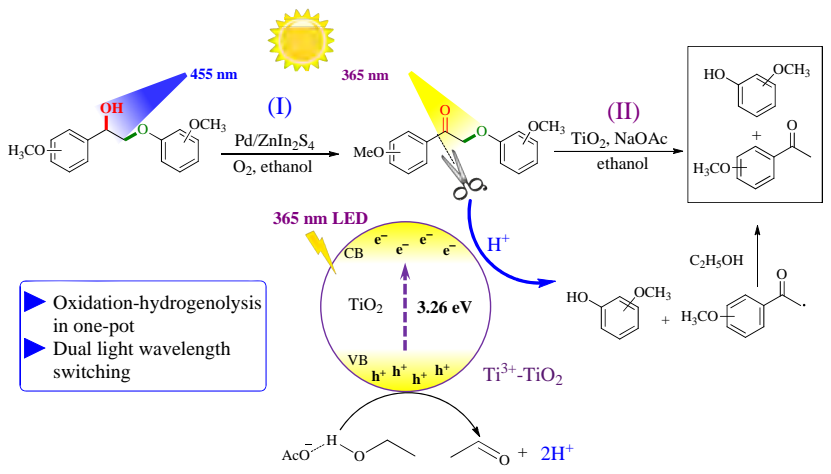

Fig. 3. Proposed reaction mechanism for photocatalytic $\mathrm{C}_{\beta}-\mathrm{OAr}$ bond cleavage of $\beta-0-4$ ketones over the $\mathrm{Ti}^{3+}-\mathrm{TiO}_{2}$. The figure was adapted from Ref. [9], Copyright (C) 2016 American Chemical Society. 


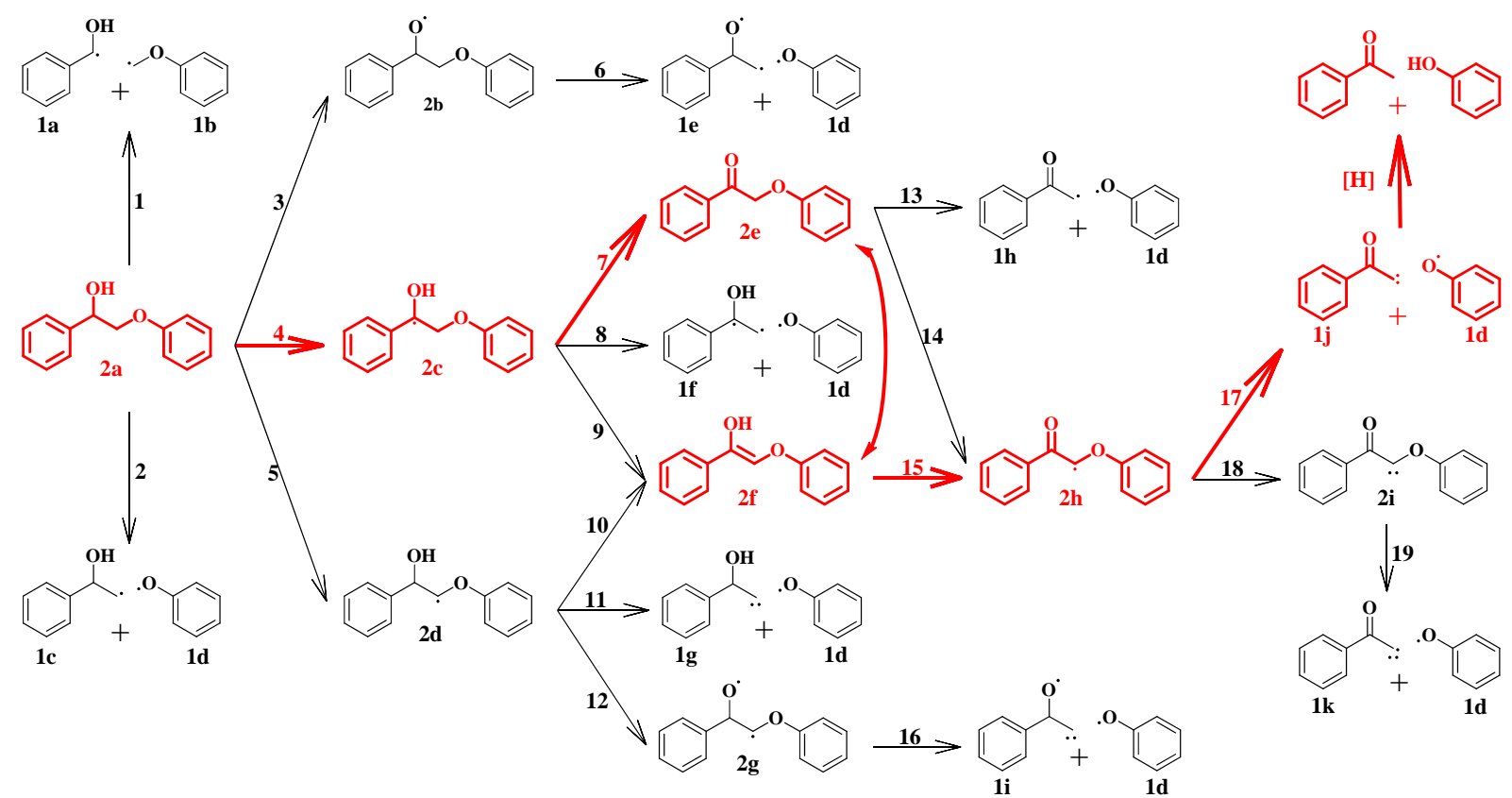

Fig. 4. Reaction network for the $\beta-0-4$ bond cleavage of 2-phenoxy-1-phenylethanol over Pd(111) surface. The figure was adapted from Ref. [15], Copyright () 2016 American Chemical Society.
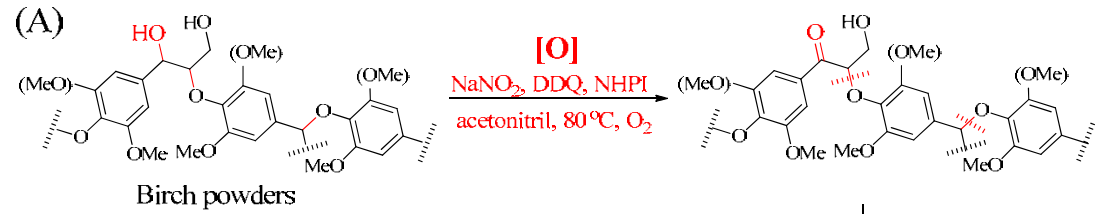

Birch powders
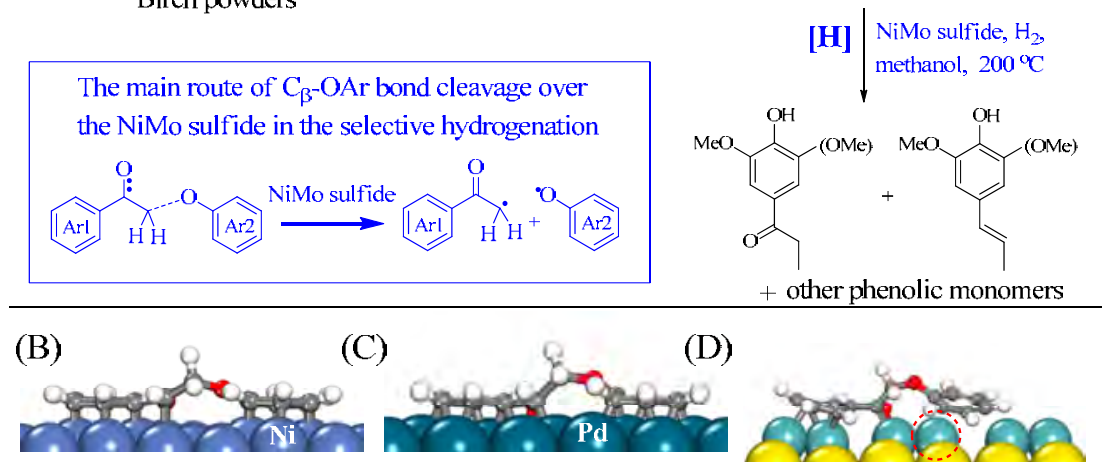

(C)

(D)
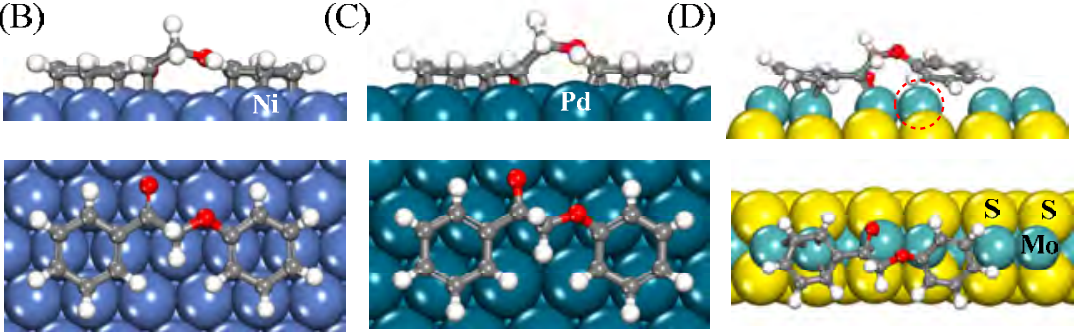

Fig. 5. (A) Conversion of birch powder to aromatic phenolic monomers via an oxidation-hydrogenation strategy; The density functional theory adsorption models of 2-phenoxy-1-phenylethan-1-one on $\mathrm{Pd}(111)$ (B), Ni(111) (C) and $\mathrm{MoS}_{2}$ (Mo edge) (D). The figure was adapted from Ref. [16], Copyright (c) 2017 American Chemical Society.

side reaction centers for the hydrogenation of aromatic rings, which leads to a high yield of aromatic rings. Furthermore, if the edge Mo atoms are partly replaced by the less active $\mathrm{Ni}^{2+}$, the potential side reaction sites of $\mathrm{C}_{\alpha}=0$ hydrogenation can be reduced, and the yield of aromatic products generated from the cleavage of $\mathrm{C}_{\beta}-\mathrm{OAr}$ bond increases. Besides the transformation of lignin model compounds, the yield of phenolic monomers from birch wood is up to $32 \%$ using this two-step strategy.

For the transformation of $\beta-0-4$ lignin model, different cata- lytic routes contain different intermediaries, which can cause variations in the $\mathrm{C}_{\beta}-\mathrm{OAr}$ ether bond cleavage. The dominating factor for the $\mathrm{C}_{\beta}-\mathrm{OAr}$ bond cleavage should contain the target bond BDE of the original substrate and one of the activated intermediates [17]. In an ideal route for cleaving the $\beta-0-4$ linkage, an activated intermediate is generated after a series of activation steps with low activation energy, whose target bond has a lower energy and easily breaks in the subsequent transformations. Analyzing from the substrate molecule to an inter- 
mediate molecule, the first dehydrogenation or oxidation of $\beta-0-4$ alcohols $\left(\mathrm{C}_{\alpha}-\mathrm{OH}\right)$ to $\beta-0-4$ ketones $\left(\mathrm{C}_{\alpha}=0\right)$ has provided many efficient strategies in the $\beta-0-4$ linkage cleavage. Because the conversion of a lignin linkage model always contains fragments (radical, cation or anion), analyzing from the substrate molecule to a potential intermediate fragment may present more efficient strategies.

Combined with density functional theory calculation, we have shown that the formation of $\beta-0-4$ radical after losing a hydroxyl group at $\mathrm{C}_{\alpha}$ can greatly decrease the $\mathrm{C}_{\beta}-\mathrm{OAr} \mathrm{BDE}$ from 247.9 to $45.3 \mathrm{~kJ} / \mathrm{mol}$, facilitating its cleavage (Fig. 2). In the hydrogenation of lignin $\beta$-0-4 model, we proposed an efficient dehydroxylation-hydrogenation strategy for the $\mathrm{C}_{\beta}-\mathrm{OPh}$ bond cleavage over a NiMo sulfide catalyst (Fig. 6) [17], which is not via $\mathrm{C}_{\beta}-\mathrm{OPh}$ ether bond direct cleavage nor $\mathrm{C}_{\alpha}-\mathrm{OH}$ dehydrogenation to $\mathrm{C}_{\alpha}=0$ before the subsequent transformation. The $\beta$-0-4-A loses a hydroxyl group $\left(\mathrm{C}_{\alpha}-\mathrm{OH}\right)$ at weak and medium strong acid sites of the catalyst. The generated $\mathrm{PhCH}^{\delta+} \mathrm{CH}_{2} \mathrm{OPh}$ transforms to $\mathrm{PhCH} \cdot \mathrm{CH}_{2} \mathrm{OPh}$ by obtaining an electron from the catalyst redox cycle. Because the possible intermediate $\mathrm{PhCH} \cdot \mathrm{CH}_{2} \mathrm{OPh}$ has a much lower $\mathrm{C}_{\beta}-\mathrm{OPh}$ bond $\mathrm{BDE}$ than $\beta-0-4-A$, the $C_{\beta}-\mathrm{OAr}$ bond breaks easily and generates styrene, ethylbenzene, phenol and various ether products under a hydrogenation condition with an alcohol solvent. Toste et al. [18] reported a vanadium-catalyzed non-oxidative mechanism, and Goldman et al. [19] reported an iridium-catalyzed dehydroaryloxylation mechanism for the $\mathrm{C}_{\beta}-\mathrm{OAr}$ cleavage, in which the $\mathrm{C}_{\alpha}$ radical or $\mathrm{C}_{\alpha}-\mathrm{M}$ species was the key intermediate. However, this effect of $\mathrm{C}_{\alpha}$ radical or $\mathrm{C}_{\alpha}-\mathrm{M}$ species generation on the BDE change in $\mathrm{C}_{\beta}-\mathrm{OAr}$ bonds drew little attention in subsequent studies.

As well as the widely-used methods that focus on reducing the BDE of the target bonds to cleave the lignin linkage, establishing a feasible and controllable reaction route is also a valuable premise to achieve this goal. Modifying the substrate during the pretreatment or reaction process is a common approach to establish the desired reaction route. In some situations, these pre-modifications can cause the increase of the targeted bond BDE, but these methods can introduce new substrate sites on the substrates for further conversion.

As shown in Fig. 2, the first oxidation of $\mathrm{C}_{\alpha}-\mathrm{OH}$ to $\mathrm{C}_{\alpha}=0$ ( $\beta-0-4$ alcohol $\rightarrow$ II-1) can cause the increase of $\mathrm{C}_{\alpha}-\mathrm{C}_{\beta}$ BDE by $30 \mathrm{~kJ} / \mathrm{mol}$, but the $\mathrm{H}$ of the new generated $\mathrm{C}_{\beta}-\mathrm{H}$ can be easily abstracted, and the $\mathrm{C}_{\beta}$ can work as the substrate site to react

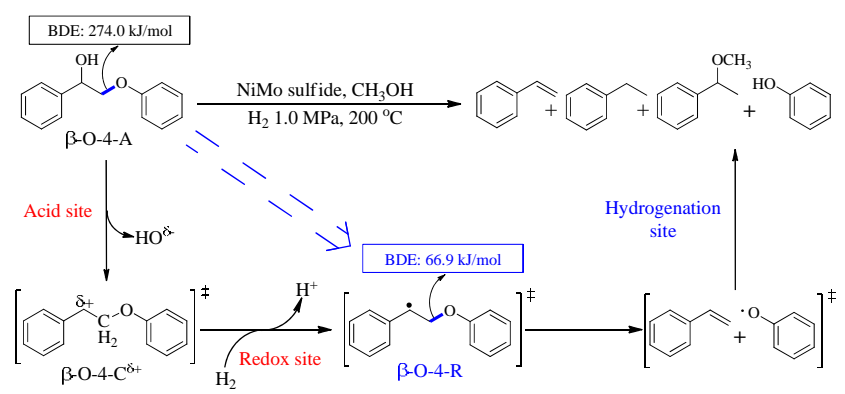

Fig. 6. Potential dihydroxylation-hydrogenation strategy for $\beta-0-4-A$ conversion over the NiMo sulfide catalyst. The figure was adapted from Ref. [17], Copyright (C) 2016 The Royal Society of Chemistry. with active oxygen species or other cleavage reagent, causing the cleavage of $\mathrm{C}_{\alpha}-\mathrm{C}_{\beta}$ bond. In our recent work, we showed that $\mathrm{Cu}(\mathrm{OAc})_{2} / 1,10$-phenanthroline [20] and $\mathrm{Cu}(\mathrm{OAc})_{2} / \mathrm{BF}_{3} \cdot \mathrm{OEt}_{2}$ [21] were effective catalysts in cleaving $\mathrm{C}_{\alpha}-\mathrm{C}_{\beta}$ bonds in $\beta-0-4$ ketones, yielding acids, esters and phenols. In-depth studies showed that $\mathrm{C}_{\beta}-\mathrm{H}$ bond activation was the rate determining step, and the substrate site $\mathrm{C}_{\beta}$ reacted with active oxygen species, generating an $\mathrm{C}_{\beta}-\mathrm{O}-\mathrm{Cu}_{2}$ intermediate (Fig. 7(A)) or an oxygen-centered radical (Fig. 7(B)) and causing the cleavage of the $\mathrm{C}_{\alpha}-\mathrm{C}_{\beta}$ bond.

The first oxidation of $\mathrm{C}_{\alpha}-\mathrm{OH}$ to $\mathrm{C}_{\alpha}=\mathrm{O}$ (II-1, Fig. 2) can introduce an active $\mathrm{C}_{\alpha}$ site, which can react with some nucleophilic cleavage reagents, such as $\mathrm{H}_{2} \mathrm{O}_{2}, \mathrm{RCOOOH}$ or $\mathrm{NH}_{2} \mathrm{OH}$, and the Baeyer-Villiger oxidation [10] or potential Bechman rearrangement can insert an $\mathrm{O}$ or $\mathrm{N}$ atom between $\mathrm{C}_{\alpha}=0$ and $\mathrm{C}_{\beta}$ or $\mathrm{C}_{1}$ of the aromatic rings. Combined with a subsequent hydrolysis process, the $C_{\alpha}-C_{\beta}$ or $A r-C_{\alpha}$ in the original $\beta-0-4$ substrate can be cleaved. The acid catalyzed dehydration at $-\mathrm{C}_{\alpha} \mathrm{HOHC} \mathrm{C}_{\beta} \mathrm{H}-$ to $\mathrm{C}_{\alpha}=\mathrm{C}_{\beta}$ can also enhance the connection between $\mathrm{C}_{\alpha}$ and $\mathrm{C}_{\beta}$, but the $\mathrm{C}_{\beta}-\mathrm{OAr}$ bond in the $\mathrm{C}_{\alpha}=\mathrm{C}_{\beta}-\mathrm{OAr}$ structure (II-2, Fig. 2) can be easily cleaved via an acidolysis process, during which the $\mathrm{H}^{+}$species attacks the $\mathrm{C}_{\alpha}$ to generate a $\mathrm{C}_{\alpha} \mathrm{H}-\mathrm{C}_{\beta}=\mathrm{O}^{+}-\mathrm{Ar}$ and weakens the connection between $\mathrm{C}_{\beta}$ and OAr [22-24]. Given that the oxidation of $\mathrm{C}_{\alpha}-\mathrm{OH}$ to $\mathrm{C}_{\alpha}=\mathrm{O}$ can reduce the $\mathrm{BDE}$ of $\mathrm{C}_{\beta}-\mathrm{OAr}$ and the simultaneous dehydration at $-\mathrm{C}_{\beta} \mathrm{HC} \mathrm{C}_{\gamma} \mathrm{H}-\mathrm{OH}$ can produce a potential $\mathrm{C}_{\gamma}=\mathrm{C}_{\beta}-\mathrm{OAr}$ for further acidolysis as discussed above, the oxidation-dehydration-acidolysis strategy is more promising than direct acidolysis. Stahl et al. [25] reported that the simple $\mathrm{HCOOH} / \mathrm{HCOONa}$ system could efficiently catalyze the cleavage of $\mathrm{C}_{\beta}-\mathrm{OAr}$ in oxidized $\beta-0-4$ linkages via a redox-neutral process, and the key intermediate (II-3, Fig. 2) contains a $\mathrm{C}_{\alpha}=\mathrm{O}$ and $\mathrm{C}_{\gamma}=\mathrm{C}_{\beta}-\mathrm{OAr}$ structure. Furthermore, the only transformation of $\mathrm{C}_{\gamma} \mathrm{HOH}$ can promote the cleavage of $\mathrm{C}_{\alpha}-\mathrm{C}_{\beta}$ via a potential retro-aldol process with an intermediate containing a $-\mathrm{C}_{\gamma} \mathrm{HO}$ (II-4, Fig. 2) [26].

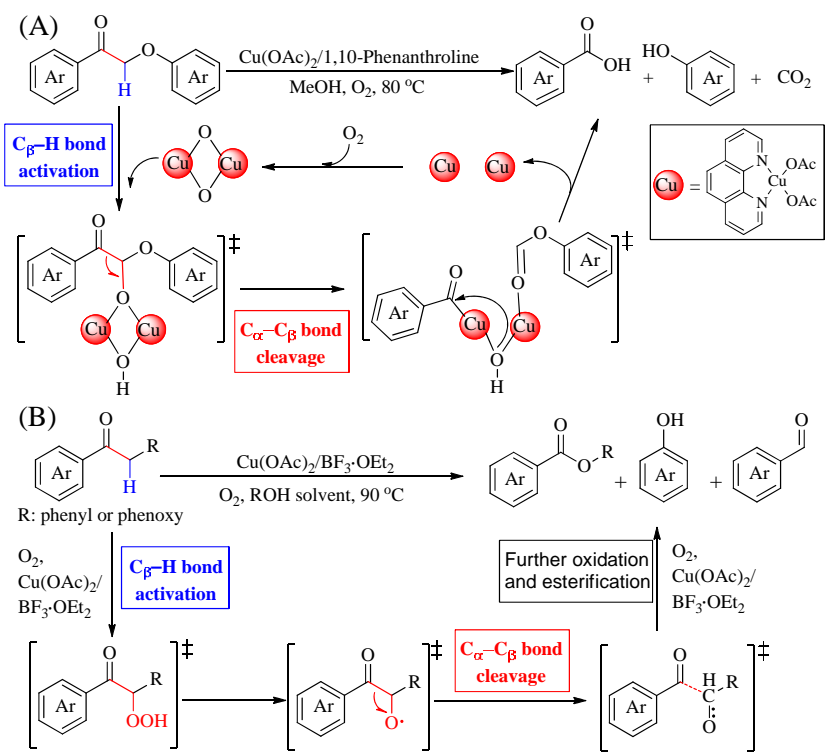

Fig. 7. Cu-catalyzed $C_{\alpha}-C_{\beta}$ bond oxidized cleavage of lignin $\beta-0-4$ model compounds. The figure was adapted from Ref. [20,21], Copyright (C 2016 American Chemical Society (A) and Copyright (C) 2017 The Royal Society of Chemistry (B). 
Although various works have been reported, there are more possibilities to further explore the cleavage strategies for the $\beta-0-4$ linkage and other lignin linkages. This perspective briefly highlights the recent progress on this topic. Referring to and summarizing these works, we have revealed the "sell a dummy" strategy for the efficient cleavage of $\beta-0-4$ linkage, which focuses on the first modification of adjacent functional group and not the direct cleavage of targeted $\mathrm{C}_{\alpha}-\mathrm{C}_{\beta}$ or $\mathrm{C}_{\beta}-\mathrm{OAr}$ bond. Two concepts, including reducing the target bond BDE and introducing a new substrate site, can provide new guidance for designing the possible reaction route, which can accelerate catalyst screening or mechanism study of lignin and lignin model conversion. Furthermore, the pre-modification of adjacent functional group can also give some guidance in restraining the lignin condensation [16,27], which can further promote the conversion of native lignin.

\section{Feng Wang}

State Key Laboratory of Catalysis, Dalian National Laboratory for Clean Energy, Dalian Institute of Chemical Physics, Chinese Academy of Sciences, Dalian 116023, Liaoning, China

Tel/Fax: +86-411-84379762

E-mail: wangfeng@dicp.ac.cn

Received 8 May 2017

Published 05 July 2017

DOI: $10.1016 /$ S1872-2067(17)62858-4

\section{References}

[1] J. Zakzeski, P. C. A. Bruijnincx, A. L. Jongerius, B. M. Weckhuysen, Chem. Rev., 2010, 110, 3552-3599.

[2] C. Z. Li, X. C. Zhao, A. Q. Wang, G. W. Huber, T. Zhang, Chem. Rev., 2015, 115, 11559-11624.

[3] R. Rinaldi, R. Jastrzebski, M. T. Clough, J. Ralph, M. Kennema, P. C. A. Bruijnincx, B. M. Weckhuysen, Angew. Chem. Int. Ed., 2016, 55, 8164-8215.

[4] Q. Song, F. Wang, J. Y. Cai, Y. H. Wang, J. J. Zhang, W. Q. Yu, J. Xu,
Energy Environ. Sci., 2013, 6, 994-1007.

[5] Q. Song, F. Wang, J. Xu, Chem. Commun., 2012, 48, 7019-7021.

[6] Q. Song, J. Y. Cai, J. J. Zhang, W. Q. Yu, F. Wang, J. Xu, Chin. J. Catal, 2013, 34, 651-658.

[7] J. D. Nguyen, B. S. Matsuura, C. R. Stephenson, J. Am. Chem. Soc., 2014, 136, 1218-1221.

[8] C. S. Lancefield, O. S. Ojo, F. Tran, N. J. Westwood, Angew. Chem. Int. $E d ., 2015,54,258-262$.

[9] N. C. Luo, M. Wang, H. J. Li, J. Zhang, H. F. Liu, F. Wang, ACS Catal,, 2016, 6, 7716-7721.

[10] A. Rahimi, A. Azarpira, H. Kim, J. Ralph, S. S. Stahl, J. Am. Chem. Soc., 2013, 135, 6415-6418.

[11] J. M. Nichols, L. M. Bishop, R. G. Bergman, J. A. Ellman, J. Am. Chem. Soc., 2010, 132, 12554-12555.

[12] M. V. Galkin, C. Dahlstrand, J. S. M. Samec, ChemSusChem, 2015, 8, 2187-2192.

[13] M. V. Galkin, J. S. M. Samec, ChemSusChem, 2014, 7, 2154-2158.

[14] X. Y. Zhou, J. Mitra, T. B. Rauchfuss, ChemSusChem, 2014, 7, 1623-1626.

[15] J. M. Lu, M. Wang, X. C. Zhang, A. Heyden, F. Wang, ACS Catal., 2016, 6, 5589-5598.

[16] C. F. Zhang, H. J. Li, J. M. Lu, X. C. Zhang, K. E. MacArthur, M. Heggen, F. Wang, ACS Catal., 2017, 7, 3419-3429.

[17] C. F. Zhang, J. M. Lu, X. C. Zhang, K. MacArthur, M. Heggen, H. J. Li, F. Wang, Green Chem., 2016, 18, 6545-6555

[18] S. Son, F. D. Toste, Angew. Chem. Int. Ed., 2010, 49, 3791-3794.

[19] M. C. Haibach, N. Lease, A. S. Goldman, Angew. Chem. Int. Ed., 2014, 53, 10160-10163.

[20] M. Wang, J. M. Lu, X. C. Zhang, L. H. Li, H. J. Li, N. C. Luo, F. Wang, ACS Catal., 2016, 6, 6086-6090.

[21] M. Wang, L. H. Li, J. M. Lu, H. J. Li, X. C. Zhang, H. F. Liu, N. C. Luo, F. Wang, Green Chem., 2017, 19, 702-706.

[22] M. R. Sturgeon, S. Kim, K. Lawrence, R. S. Paton, S. C. Chmely, M. Nimlos, T. D. Foust, G. T. Beckham, ACS Sustainable Chem. Eng., 2014, 2, 472-485.

[23] C. W. Lahive, P. J. Deuss, C. S. Lancefield, Z. H. Sun, D. B. Cordes, C. M. Young, F. Tran, A. M. Z. Slawin, J. G. de Vries, P. C. J. Kamer, N. J. Westwood, K. Barta, J. Am. Chem. Soc., 2016, 138, 8900-8911.

\section{Graphical Abstract}

Chin. J. Catal., 2017, 38: 1102-1107 doi: 10.1016/S1872-2067(17)62858-4

Sell a dummy: Adjacent functional group modification strategy for the catalytic cleavage of lignin $\beta-0-4$ linkage

Chaofeng Zhang, Feng Wang *

Dalian Institute of Chemical Physics, Chinese Academy of Sciences

This perspective highlights recent progress on lignin $\beta-0-4$ conversion, which focuses on the combinatorial strategies leading to lignin $\beta-0-4$ cleavage beginning with adjacent functional group modification, and provides insight into the challenges unexplored in this area.

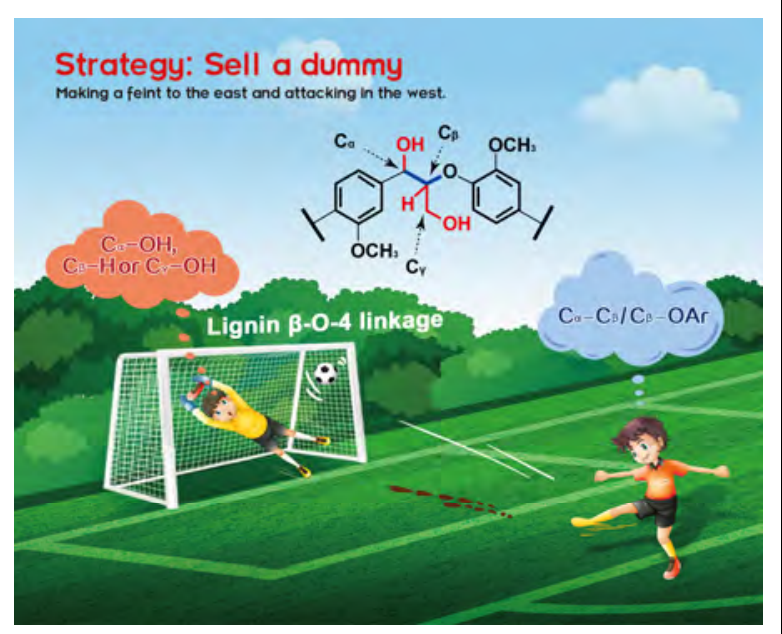


[24] P. J. Deuss, M. Scott, F. Tran, N. J. Westwood, J. G. de Vries, K. Barta, J. Am. Chem. Soc., 2015, 137, 7456-7467.

[25] A. Rahimi, A. Ulbrich, J. J. Coon, S. S. Stahl, Nature, 2014, 515, 249-252.

[26] S. vom Thorsten, T. den Hartog, J. Buendia, S. Stoychev, J. Mottwei- ler, C. Bolm, J. Klankermayer, W. Leitner, Angew. Chem. Int. Ed., 2015, 54, 5859-5863.

[27] L. Shuai, M. T. Amiri, Y. M. Questell-Santiago, F. Héroguel, Y. Li, H. Kim, R. Meilan, C. Chapple, J. Ralph, J. S. Luterbacher, Science, 2016, 354, 329-333.

\title{
声东击西：针对木质素及-O-4连接结构裂解的邻近基团转化策略

\author{
张超锋, 王 峰*
} \\ 中国科学院大连化学物理研究所催化基础国家重点实验室, 洁净能源国家实验室(筹), 辽宁大连 116023
}

\begin{abstract}
摘要: 木质素作为一种潜在可替代石油制备芳香化合物的可再生资源, 其转化利用一直受到广泛的关注. 在多种木质素链 接结构中, $\beta$-O-4连接占 $40 \%$ 60\%, 因此被认为是木质素降解转化过程中需要被首先断裂的结构. 近来, 相比于直接研究真 实木质素的复杂转化过程, 另外一种通过研究木质素模型分子转化规律的“自下而上策略”已经为木质素转化提供了许多 新的转化思路及组合策略. 本文对这些组合策略进行了简要的总结, 并提出了更具概括性的“声东击西策略”. 简要地说, 通过预先转化目标 $\mathrm{C}_{\alpha}-\mathrm{C}_{\beta}$ 及 $\mathrm{C}_{\beta}-\mathrm{OAr}$ 键的邻近化学基团, 从而降低目标化学键的键解离能或在底物分子中引入“底物位点”, 进一步促进目标化学键的高效选择性转化. 以底物分子到中间体分子的角度分析, 将 $\mathrm{C}_{\alpha}-\mathrm{OH}$ 转化为 $\mathrm{C}_{\alpha}=\mathrm{O}$ 可有效降低目标 化学键 $\mathrm{C}_{\beta}-\mathrm{OAr}$ 的键解离能, 针对这一点, 本文介绍了“氧化-(光催化)还原策略”, “内转氢策略”以及“氧化-选择性加氢策略”. 同时, 针对降低目标化学键的思路, 本文还从底物分子到中间体分子碎片角度分析介绍了“脱羟-加氢策略”. 针对向底物分 子中引入 “底物位点”的思路, 本文首先介绍了 “氧化-氧化策略”, 将 $\mathrm{C}_{\alpha}-\mathrm{OH}$ 转化为 $\mathrm{C}_{\alpha}=\mathrm{O}$ 虽然增加了 $\mathrm{C}_{\alpha}-\mathrm{C}_{\beta}$ 键的 $\mathrm{BDE}$, 但与 $\mathrm{C}_{\alpha}=\mathrm{O}$ 相连的 $\mathrm{C}_{\beta}$ 位点脱氢后可与高活性氧物种结合, 从而更有效的裂解 $\mathrm{C}_{\alpha}-\mathrm{C}_{\beta}$ 键. 此外, 本文简要介绍了类似情况下的过氧 物种进攻 $\mathrm{C}_{\alpha}=\mathrm{O}$ 的“氧化-BV氧化策略”, 以及“直接酸解策略”和“氧化-脱水-酸解策略”. 虽然目前针对木质素 $\beta-O-4$ 连接结构 的转化策略已有较多的报道, 但仍然存在着很多值得探索的可能性, 该“声东击西策略”可能为进一步的高效反应路径设计, 催化剂笁选及机理研究提供指导. 同时, 这种邻近基团预转化的策略也能为防止木质素再聚提供方案, 从而促进真实木质 素的高效转化.
\end{abstract}

关键词: 木质素; $\beta-O-4$; 芳香化学品; 醚键断裂; C-C键断裂

收稿日期: 2017-05-08. 接受日期: 2017-05-16. 出版日期: 2017-07-05.

*通讯联系人. 电话/传真: (0411)84379762; 电子信箱: wangfeng@dicp.ac.cn

基金来源：中国科学院战略性先导科技专项项目(XDB17020300); 国家自然科学基金(21422308); 辽宁省科技厅 (2015020086-101).

本文的英文电子版由Elsevier出版社在ScienceDirect上出版(http://www.sciencedirect.com/science/journal/18722067). 